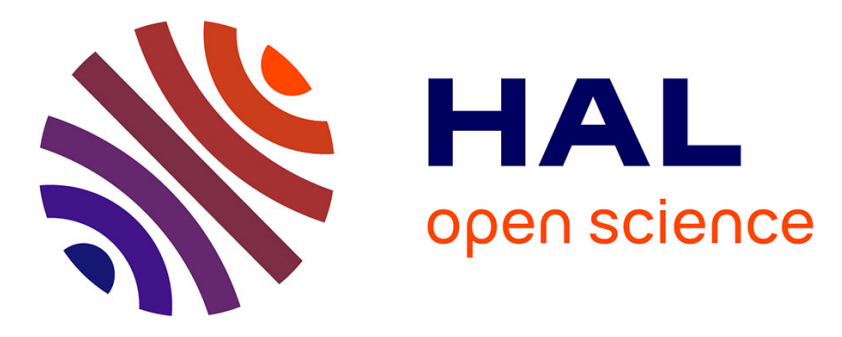

\title{
Edematous myositis: a clinical presentation first suggesting dermatomyositis diagnosis
}

Mathilde Duchesne, Sarah Leonard-louis, Océane Landon-cardinal, Céline Anquetil, Kuberaka Mariampillai, Quentin Monzani, Olivier Benveniste, Yves Allenbach

\section{To cite this version:}

Mathilde Duchesne, Sarah Leonard-louis, Océane Landon-cardinal, Céline Anquetil, Kuberaka Mariampillai, et al.. Edematous myositis: a clinical presentation first suggesting dermatomyositis diagnosis. Brain Pathology, 2020, bpa.12844. 10.1111/bpa.12844 . hal-03523548

\section{HAL Id: hal-03523548 https: / hal.sorbonne-universite.fr/hal-03523548}

Submitted on 12 Jan 2022

HAL is a multi-disciplinary open access archive for the deposit and dissemination of scientific research documents, whether they are published or not. The documents may come from teaching and research institutions in France or abroad, or from public or private research centers.
L'archive ouverte pluridisciplinaire $\mathbf{H A L}$, est destinée au dépôt et à la diffusion de documents scientifiques de niveau recherche, publiés ou non, émanant des établissements d'enseignement et de recherche français ou étrangers, des laboratoires publics ou privés. 
RESEARCH ARTICLE

\title{
Edematous myositis: a clinical presentation first suggesting dermatomyositis diagnosis
}

\author{
Mathilde Duchesne ${ }^{1,2,3, *}$ (ID) ; Sarah Leonard-Louis ${ }^{4,5}$; Océane Landon-Cardinal6; Céline Anquetil7; \\ Kuberaka Mariampillai7; Quentin Monzani8; Olivier Benveniste7; Yves Allenbach ${ }^{7,9}$ \\ ${ }^{1}$ Department of Pathology, University Hospital of Limoges, Limoges, France. \\ 2 Laboratory of Neurology, University Hospital of Limoges, Limoges, France. \\ ${ }^{3}$ EA6309, University of Medicine and Pharmacology of Limoges, Limoges, France. \\ ${ }^{4}$ Department of Neuropathology, APHP, Pitié-Salpêtrière University Hospital, Sorbonne University, University Pierre et Marie Curie, Paris, France. \\ ${ }^{5}$ Department of Neuromyology, National Reference Center of Neuromuscular Disorders, APHP, Pitié-Salpêtrière University Hospital, Sorbonne \\ University, University Pierre et Marie Curie, Paris, France. \\ ${ }^{6}$ Division of Rheumatology and Research Center, Centre Hospitalier de l'Université de Montréal, Montreal, Quebec Canada. \\ 7 Department of Internal Medicine and Clinical Immunology, National Reference Center of Neuromuscular disorders, APHP, Pitié-Salpêtrière University \\ Hospital, Sorbonne University, University Pierre et Marie Curie, Paris, France. \\ ${ }^{8}$ Department of Radiology, APHP, Pitié-Salpêtrière University Hospital, Sorbonne University, University Pierre et Marie Curie, Paris, France. \\ 9 INSERM, UMR974, Sorbonne University, University Pierre et Marie Curie, Paris, France.
}

\section{Keywords}

autoantibodies, complement, dermatomyositis, edema, myositis, vasculopathy.

Corresponding author:

Mathilde Duchesne, MD, Department of

Pathology, University Hospital of Limoges,

2 Avenue Martin Luther King, Limoges,

France (E-mail: mathilde.duchesne@unilim.fr)

Received 13 January 2020

Accepted 14 April 2020

Published Online Article

Accepted 00 Month 2020

doi:10.1111/bpa.12844

\begin{abstract}
Aims: Edema of the limbs is uncommon in idiopathic inflammatory myopathies (IIM). The few reported cases have been associated with severe and refractory dermatomyositis (DM), sometimes in association with cancers. We aimed to determine if edematous myositis is a homogeneous subtype based on clinical, serological and pathological features. Methods: This is a retrospective observational study performed between 2008 and 2015 in the French national referral center for myositis. All adult patients with an inflammatory muscle biopsy and upper limbs edema were included as well as IIM cases without limb edema as controls. Clinical, biological and pathological features were collected. Results: Seventeen edematous myositis were included and compared to 174 IIM without edema, including 50 DM controls. Edema was the first manifestation in $23 \%$ of patients. Muscle weakness was severe and symmetric, $71 \%$ of patients presented dysphagia and a restrictive ventilatory pattern was found in $40 \%$. Fifty-two percent of patients had a typical DM skin rash and $23 \%$ had cancer within 3 years of diagnosing myositis. Fifty-three percent of patients presented a myositis specific antibody and only DM-specific antibodies were detected. Classic pathological DM features (perifascicular atrophy, perifascicular/perimysial perivascular inflammation) were uncommon but capillary C5b-9 deposition and MxA expression were seen in $79 \%$ and $73 \%$ of cases, respectively. A perimysial edema was found in $82 \%$ of cases. Seventeen percent of patients died (median follow up of 18 months). Edematous myositis demonstrated more marked capillary C5b-9 deposition compared to IIM controls. There was no clinical, biological or pathological difference with DM controls except for limb edema. Conclusion: Our study underlines that limb edema could be a symptom of IIM and that edematous myositis are mostly DM. The vasculopathy seems to play a key role in its pathophysiology. Limb edema associated with muscle impairment should suggest the diagnosis of DM in clinical settings.
\end{abstract}

\footnotetext{
Abbreviations: ALP, alkaline phosphatase reaction; ASyS, anti-synthetase syndrome; CAM, cancer-associated myositis; CK, creatine kinase; COX/ $\mathrm{SDH}$, cytochrome oxidase/ succinate deshydrogenase; CS, corticosteroids; DM, dermatomyositis; EMG, electromyography; GT, Gomori trichrome; HES, Hematoxylin-Eosin-Safran; HMGCR, hydroxymethylglutaryl-Coenzyme A reductase; IBM, inclusion body myositis; IIM, idiopathic inflammatory myopathy; IMNM, immune-mediated necrotizing myopathy; IVIg, immunoglobulin intravenous; MDA5, melanoma differentiation-associated gene 5; MAA, myositis-associated antibodies; MHC, major histocompatibility complex; MRI, magnetic resonance imaging; MSA, myositis-specific antibodies; MxA, Myxovirus resistance protein A; NXP2, nuclear matrix protein 2; PFTs, pulmonary function test; PM, polymyositis; SAE, small ubiquitin-like modifier activating enzyme; SRP, signal recognition particle; TIF1 $\gamma$, transcriptional intermediary factor $1 \gamma$; TTE, transthoracic echocardiogram.
} 


\section{INTRODUCTION}

Idiopathic inflammatory myopathies (IIM) are a heterogeneous condition involving the skeletal muscle but also displaying extra-muscular features. Recently, myositis-specific antibodies (MSA) have been identified and permitted to refine classification criteria (4,21-22,28). Using a clinico-serological and/or pathological approaches, IIM were classified into: dermatomyositis (DM), inclusion body myositis (IBM), and polymyositis (PM) (28) or immune-mediated necrotizing myopathy (IMNM), and anti-synthetase syndrome (ASyS) (22). Among the extra-muscular features, only the presence of a classical DM skin rash has been included as a classification criterion $(21,28)$ yet other skin manifestations have been described in IIM.

Beside the mechanics' hands, which are mainly associated with ASyS (24), the presence of edema of the limbs has also been reported in IIM patients. To date, only a limited number of edematous myositis patients have been reported (23) and the presence of anti-NXP2 antibodies has been associated with limb edema in DM patients (1). Nonetheless, edematous myositis may be encountered in the absence of anti-NXP2 and few detailed clinico-sero-pathological descriptions of these cases have been reported $(17,23,34,38)$. Whether edematous myositis belongs to the spectrum of DM or represents a distinct subgroup of IIM patients remains to be clarified.

Our objective was, therefore, to assess the clinical characteristics (muscular and cutaneous features, cancer association, treatment response and clinical evolution), biological features (creatine kinase (CK) level, autoantibody association) and pathological findings (morphological abnormalities, inflammation profile, vasculopathy features) in edematous myositis compared to IIM controls without limb edema.

\section{MATERIALS AND METHODS}

\section{Patients}

This is a retrospective study performed at the French national referral center for myositis. The inclusion criteria were: age $>18$ years, inflammation on muscle biopsy (13) and clinical edema involving at least the upper limb (in order to rule out patients presenting with non-specific lower limb edema). The exclusion criteria were: severe kidney, liver or heart failure, as well as patients with systemic sclerosis since edema may be a feature at disease onset. IMNM, DM and anti-synthetase patients based on clinico-serological and/or clinico-pathological criteria $(2,21,28)$ without clinical limb edema were included as controls.

\section{Data collection}

Medical records were retrospectively reviewed to collect the following data: age at first symptoms, muscular and/or cutaneous features, presence of extra-cutaneomuscular features (weight loss, arthralgia/arthritis, lung involvement, malignancy occurring within 3 years of diagnosing myositis - defining cancer-associated myositis [CAM] (9) -) as well as treatments and clinical outcomes.

Thorax CT scan, pulmonary function tests (PFTs), transthoracic echocardiogram (TTE), electromyography (EMG) and muscle magnetic resonance imaging (MRI) were collected. Additionally, the following biological data were collected: creatine kinase (CK), C-reactive protein (CRP), and myositis-specific and myositis-associated antibodies (MSA/ MAA). MSA were detected as previously reported (22) and included the following: anti-SAE (small ubiquitin-like modifier activating enzyme), -TIF1 $\gamma$ (transcriptional intermediary factor $\gamma$ ), -NXP2 (nuclear matrix protein 2), -MDA5 (melanoma differentiation-associated gene 5), -Mi-2 (nucleosome remodeling and histone deacetylase protein complex), -Jo1 (histidyl-tRNA-synthetase), -PL-12 (alanyl-tRNA-synthetase), -PL-7 (threonyl-tRNA-synthetase), -signal recognition particle (SRP), -hydroxyméthylglutaryl-Coenzyme A reductase (HMGCR), -OJ (isoleucyl-tRNA-synthetase) and -EJ (glycyl-tRNA-synthetase). The presence of MAA was screened using HEP-2 cells before any characterization. The positivity threshold for antinuclear antibodies (ANA) was $1 / 160$.

\section{Pathological analysis}

Histological material was fixed in formalin and embedded in paraffin, and frozen. The paraffin sections were cut to 3-4 $\mu \mathrm{m}$ and frozen sections were cut to 8-10 $\mu \mathrm{m}$. The standard colorations included Hematoxylin-Eosin-Safran (HES) for paraffin, Hematoxylin-Eosin (HE) and Gomori trichrome (GT) for freezing. An immunohistochemical (IHC) study was completed using an autostainer (VENTANA BenchMark ULTRA fully, Ventana Medical Systems, Inc.) to characterize the inflammatory infiltrate (on paraffin samples): anti-CD3 (Rabbit, clone 2GV6, Roche), anti-CD20 (Mouse, clone L26, Dako), anti-CD8 (Mouse, clone C8/144B, Dako) and anti-CD68 (Mouse, clone KP1, Dako), as well as vasculopathy (on frozen samples): anti-MHC class I (Mouse, clone CR3/43, Dako), anti-MxA (Mx1/2/3 [H-285, sc-50509], 1:100 dilution, Santa Cruz Biotechnology, USA), anti-C5b-9 (Mouse, clone aE11, Dako), anti-MHC class II (mouse, clone C3/43; Dako), anti-CD34 (Mouse, clone Qbend10, Dako) and the double anti-CD34/C5b-9 labeling. Finally, histo-enzymology was performed manually on frozen samples in order to eliminate mitochondrial abnormalities via double COX/SDH (cytochrome oxidase/ succinate dehydrogenase) labeling and in order to search for an expression of alkaline phosphatase (ALP) in the perimysial interstitial tissue as a marker of edema within the muscle.

All slides were retrospectively reviewed by two neuropathologists in double blind (M.D., S.L.-L.) and carried out using optical microscopy (OM). Analysis included: morphological analysis of the muscle samples on HES, GT and ALP staining (using the SK-5300 Vector Blue kit revealing ALP activity in blue, associated with eosin counterstaining to mark the cytoplasm of muscle cells). Evaluation of both necrosis-regeneration and interstitial 
edema was performed using a semi-quantitative scale (+ to +++ ); characterization of inflammatory infiltrates localization on HES staining with the measurement of the density of immune cells calculated after counting positive cells from the whole area of the biopsy specimen on IHC staining (anti-CD3, anti-CD8, anti-CD20 and anti-CD68) expressed as a ratio; analysis of the expression of the MHC class I and MxA; then the characterization of the vasculopathy on HES (perifascicular atrophy, microinfarct) and with the anti-C5b-9 (deposition on the endomysial capillaries).

\section{Ultrastructural analysis}

Performed after fixation in $2.5 \%$ glutaraldehyde for 48 hours at $4^{\circ} \mathrm{C}$, post-fixation in $1 \%$ osmium tetroxide and embedding of the muscle tissue in epoxy. Semithin sections $(1 \mu \mathrm{m})$ were stained with toluidine blue. Ultrathin sections $(90 \mathrm{~nm})$ were stained with lead citrate and uranyl acetate then observed under an electron microscope (JEOL 1011). Analysis was performed at the Limoges University Hospital in the Pathology Department by one neuropathologist (M.D.). For each case, 10 to 15 vessels have been analyzed.

\section{Statistics}

Statistical analysis was descriptive: mean, standard deviation and frequencies were calculated using GraphPad Prism software version 6.00 (GraphPad Software, La Jolla, CA) and $\mathrm{R}$ version 3.6.0 (RCore6team). Categorical variables were reported as numbers and/or percentages and quantitative variables were reported as median [first quartile; third quartile]. Nonparametric tests were performed to compare qualitative and quantitative data to control groups. A $P$-value $<0.05$ was considered statistically significant. The $P$-value was adjusted by the Benjamini-Hochberg procedure.

\section{Ethics statements}

Approval was obtained from the French Ministry of Research (AC-2013-1868, CTTIRS 14.323) and the National Commission for Informatics and Liberties (CNIL 915139). This study was approved by the research ethics committee of the Pitié-Salpêtrière Hospital.

\section{RESULTS}

\section{Patients' characteristics}

Seventeen patients were included $(7,10)$ with a median age of 52 [44-60] at diagnosis. Three patients presented at least another autoimmune disease (type 1 diabetes, Hashimoto's disease, systemic lupus erythematosus, primary biliary cirrhosis and celiac disease). Two patients were treated concomitantly with calcium channel blockers, but edema did not resolve after the medication withdrawal. One patient was unable to have a muscle biopsy performed because of his precarious health condition. Patients' characteristics are available in the Supporting Table S1.

\section{Muscle features}

Muscle involvement was the first manifestation in $53 \%$ of the cases. Edema was the first manifestation in $23 \%$ of cases $(n=4 / 17)$ : two with edema only and the two others with skin rash. Both muscle and cutaneous involvement occurred concomitantly in the four remaining cases. The median time between symptom onset and muscle biopsy was $2[1 ; 5]$ months.

Most patients presented myalgia (88\%) and muscle weakness was reported in $83 \%$ of patients (Table 1). Muscle weakness was symmetric and severe at presentation as half of the patients had an MRC-5 score $\leq 2$ and median score was 2 [2; 3.5]. A third of patients were bedridden at presentation.

Seventy percent of patients presented dysphagia and $40 \%$ $(n=6 / 15)$ had a restrictive ventilatory pattern. The median CK level at the disease onset was 5118 [1412; 6964] IU/L. All patients $(n=14 / 14)$ had a myopathic pattern on EMG. T2-STIR hyperintensity on muscle MRI was found in $75 \%$ of patients $(n=7 / 9)$ and extended into subcutaneous tissues in 55\% $(\mathrm{n}=5 / 9)$ of cases (see Figure 1A,B). One patient $(n=1 / 9)$ presented a hyperintensity of the fascia (Figure 1B).

\section{Cutaneous features}

Edema involved all four limbs in $65 \%$ of cases while it involved only a single limb in $11.8 \%$ of cases (Table 2; Figure 1C). Proximal and distal edema was found in 59\% of patients, while it was restricted to the distal or proximal region in $23 \%$ and $18 \%$ of cases, respectively. Edema was described as painful in half of the cases. Facial edema was also observed in $41 \%$ of patients and involved the eyelids in $35 \%$ of them.

Forty-seven percent of patients had classic DM skin rashes including heliotrope rash $(\mathrm{n}=7 / 8)$, periungueal erythema $(n=5 / 8)$, Gottron papules $(n=4 / 8)$, holster sign $(n=2 / 8)$ and flagellate erythema in hand $(n=1 / 8)$ (Table 2). Finally, shawl sign, thigh, scalp, facial and erythema in relation to the joints were more rarely reported,

Table 1. Muscle features in edematous myositis

\begin{tabular}{lc}
\hline Variables & $\%(\mathrm{n})$ or median $[01 ; \mathrm{O} 3]$ \\
\hline Myalgia & $35.3 \%(6 / 17)$ \\
Proximal muscle weakness & $82.3 \%(14 / 17)$ \\
Axial weakness & $29.4 \%(5 / 17)$ \\
Dysphagia & $70.6 \%(12 / 17)$ \\
MRC-5 muscle scale & $2[2 ; 5]$ \\
CK level (IU/L) & $5118[1654 ; 6928]$ \\
Myopathic EMG & $100 \%(14 / 14)$ \\
Bedridden & $35.3 \%(6 / 17)$ \\
\hline
\end{tabular}

Abbreviations: ENMG = electromyography; $\mathrm{MRC}=$ Medical Research Council. 


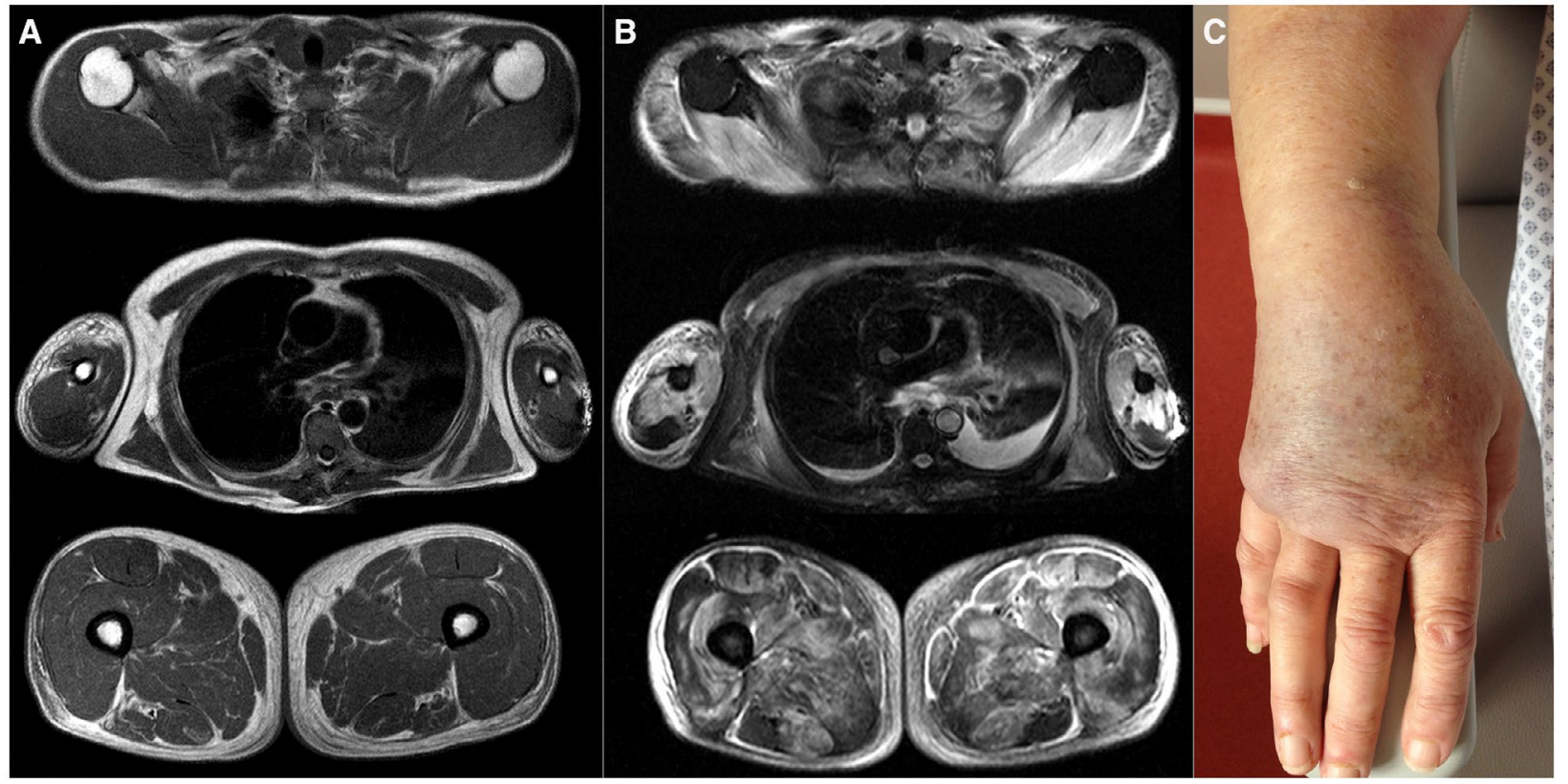

Figure 1. Edema of the limb on $\mathrm{MRI}(\mathrm{A}$ and $\mathrm{B})$ and on clinical examination (C). A and B: Axial plane, three levels of acquisition, $T 1$ sequence $(A)$ and T2-STIR sequence (B). On the three levels of acquisition (above at the level of the shoulders, a little lower at the level of the thorax and the middle part of the arms and even lower at the level of the proximal root of the two thighs) there is an edematous infiltration with an almost normal T1 (A) signal but a T2-STIR hypersignal of the peripheral subcutaneous tissue around muscle and bone. Almost all the muscles are in T2-STIR hyperintensity (B), reflecting an edema due to myositis. Hyperintensity of the fascia can also be observed, but this image was not observed in the other patients. There is no significant fatty involution or amyotrophy evoking an older involvement. C: edema of the limb of a patient with myositis

diffuse (Figure 2A). Microinfarction was observed in a quarter of cases (Figure 2B). Only 12\% of cases had perifascicular atrophy (Figure 2C). All patients presented inflammatory infiltrates located in the perimysium $(100 \%)$, endomysium (81\%) and perivascular (81\%) areas (Figure 2D,E). No inflammatory infiltrate invading nonnecrotic fibers was observed. $\mathrm{T}$ cells were detected in most cases $(94 \%)$ with a majority of $\mathrm{CD}^{+} \mathrm{T}$ cells in $67 \%$ ( $\mathrm{n}=10 / 15$ ) of cases, while $\mathrm{CD}^{+} \mathrm{T}$ cells were dominant in only $13 \%(n=2 / 15)$ of them. Finally, macrophages were detected in a third of the cases. Perimysial edema with positive histo-enzymological ALP reaction (Figure 2F) was observed in $82 \%$ of cases $(n=9 / 11)$. Blood vessels in the perimysium were dilated in $75 \%(n=12 / 16)$ of the cases (Figure 2A,C). Enlarged capillaries were observed in $73 \%$ $(n=11 / 15)$ of the cases, in a diffuse way without predominantly perifasicular. In one case, the morphological analysis of the endomysial capillaries was difficult due to the significant destruction of the muscle tissue. In addition, there was systematically a discrete to moderate positivity of ALP in the endomysial capillaries. There were no mitochondrial abnormalities, no rimmed vacuoles and no ragged red fibers. MHC class I was expressed diffusely and intensely (sarcolemmal and sarcoplasmic) in $79 \%$ of cases $(n=11 / 14)$, with a perifascicular enhancement in one patient (Figure 3A), while an isolated perifascicular expression was observed in two others. MHC class II was negative in all cases. Strikingly, endomysial capillary C5b-9 deposition was intense and found 
Table 2. Extramuscular impairment of patients with edematous myositis

\begin{tabular}{lc}
\hline Variables & $\%(\mathrm{n})$ or median [Q1; Q3] \\
\hline Muscle involvement as the first symptom & $52.9 \%(9 / 17)$ \\
Edema as the first symptom & $23.5 \%(4 / 17)$ \\
Both muscle and edema concomitantly & $23.5 \%(4 / 17)$ \\
Edema involvement & \\
All four limbs & $64.7 \%(11 / 17)$ \\
Restricted to one limb & $11.8 \%(2 / 17)$ \\
Proximal and distal & $58.8 \%(10 / 17)$ \\
Proximal & $17.6 \%(3 / 17)$ \\
Distal & $23.5 \%(4 / 17)$ \\
Facial & $41.2 \%(7 / 17)$ \\
Eyelids & $35.3 \%(6 / 17)$ \\
Typical DM rash & $47.1 \%(8 / 17)$ \\
Ventricular ejection fraction (\%) & $63.5[46 ; 74]$ \\
BNP (IU/L) & $71[24 ; 178]$ \\
Protein level (g/L) & $60[54.5 ; 67.83]$ \\
Albumin level (g/L) & $30[24 ; 35.73]$ \\
Proteinuira & $0 \%(0 / 17)$ \\
Weight loss & $52.9 \%(9 / 17)$ \\
Arthralgia & $29.4 \%(5 / 17)$ \\
Arthritis & $0 \%(0 / 17)$ \\
Interstitial lung disease & $5.9 \%(1 / 17)$ \\
Positive MSA & $53.3 \%(8 / 15)$ \\
NXP2 & $25 \%(2 / 8)$ \\
NXP2-SAE & $12.5 \%(1 / 8)$ \\
Mi-2 & $12.5 \%(1 / 8)$ \\
SAE & $12.5 \%(1 / 8)$ \\
TIF1 $\gamma$ & $37.5 \%(3 / 8)$ \\
Cancer & $23.5 \%(4 / 17)$ \\
Other autoimmune disease & $17.6 \%(3 / 17)$ \\
\hline Abbrevions: & \\
\hline
\end{tabular}

Abbreviations: $\mathrm{BNP}=$ brain natriuretic peptide; $\mathrm{DM}=$ dermatomyositis.

diffusely in $77 \%$ of cases $(n=11 / 14$ ) (Figure $3 B$ ). Only a single patient did not show any C5b-9 deposition. Finally, MxA expression was positive in $73 \%$ of cases $(n=8 / 11)$ (Figure 3C,D), with a perifascicular enhancement in a third of them $(37 \% ; n=3 / 8)$.

\section{Ultrastructural analysis}

Electron microscopy analysis was performed for seven patients and four of whom were MSA positive. Most of the patients $(64 \% ; n=7 / 11)$ had endothelial tubuloreticular inclusions. In two cases, the vessels were largely destroyed, not allowing an optimal search for inclusions. In addition, all the patients presented a lot of vesicles of pinocytosis and the basement membrane around the capillaries was frequently thickened (Supporting Figure S1).

\section{Patients' outcome}

Most patients $(88 \% ; n=15 / 17)$ were treated with corticosteroids (CS) and intravenous immunoglobulin (IVIg) was received in $71 \%$ of patients. Combination with an immunosuppressant (methotrexate, azathioprine or mycophenolate mofetil) was performed in most of patients $(80 \% ; n=12 / 15)$. One patient received IVIg monotherapy and another was too ill, because of cancer progression, to receive any immunosuppressive treatment. Finally, half of the patients $(n=8 / 16)$ needed treatment intensification to control the muscle disease.

The median follow-up duration was 18 [5.5; 49.5] months. Seventeen percent of patients died during this period, all related to malignancy and the average time from myositis diagnosis to death was $6[2 ; 11]$ months. Only one patient with a CAM (breast cancer) survived and was in the remission of both cancer and myositis after 81 months of followup. After 18 months of follow-up, only $22 \%$ of patients $(n=2 / 9)$ were in remission without treatment.

\section{Comparison of edematous myositis to IIM controls}

Edematous myositis was compared to 174 IIM controls without limb edema (Table 3). Eyelids rash was more frequent in edematous myositis $(29 \%$ vs. $5 \%, P=0.002)$ as well as capillary C5b-9 deposition compared to controls $(P=003)$. Moreover, DM-specific antibodies were significantly more frequent in edematous myositis $(P<0.00001)$. Edematous myositis was also compared to $50 \mathrm{DM}$ controls without edema (Table 4). There was no clinical, biological or pathological difference between these groups except for limb edema.

\section{DISCUSSION}

We demonstrated that edematous myositis is a relatively homogeneous clinical phenotype characterized by a severe myopathy (severe muscle weakness frequently associated with dysphagia) with a high mortality rate related to a high risk of malignancy. Edematous myositis could belong to the spectrum of DM since $82.4 \%$ of the patients $(n=14 / 17)$ presented at least one of the typical DM features (skin rash, DM-specific antibodies and/or myopathological pattern as perifascicular atrophy, perimysial inflammatory infiltrate and/or sarcoplasmic MxA positivity). An intense endomysial capillary C5b-9 deposition was the main pathological findings in our cohort and this finding was significantly different from controls except for non-edematous DM controls. Finally, three cases (cases 3, 4 and 6; see Supporting Table S1) did not have clinical, serological or pathological characteristics of DM, despite the positivity of C5b-9 on capillaries concerning cases 3 and 6 , which was not sufficient to diagnose DM $(7,31)$, and tubuloreticular inclusions concerning cases 4 and 6.

Edematous myositis has only been rarely reported in the literature since its first description in $1886-87$ by Wagner (33) and Hepp (12) who reported limb edema as a possible sign associated with polymyositis. In our study, 17 cases were included based on strict inclusion criteria (upper limb edema) and exclusion criteria (conditions associated with increased hydrostatic pressure) in order to avoid non-specific edema, but to our knowledge, it is the largest series of edematous DM patients.

Our results are consistent with the previously published cases, describing a disabling disease with severe muscle 


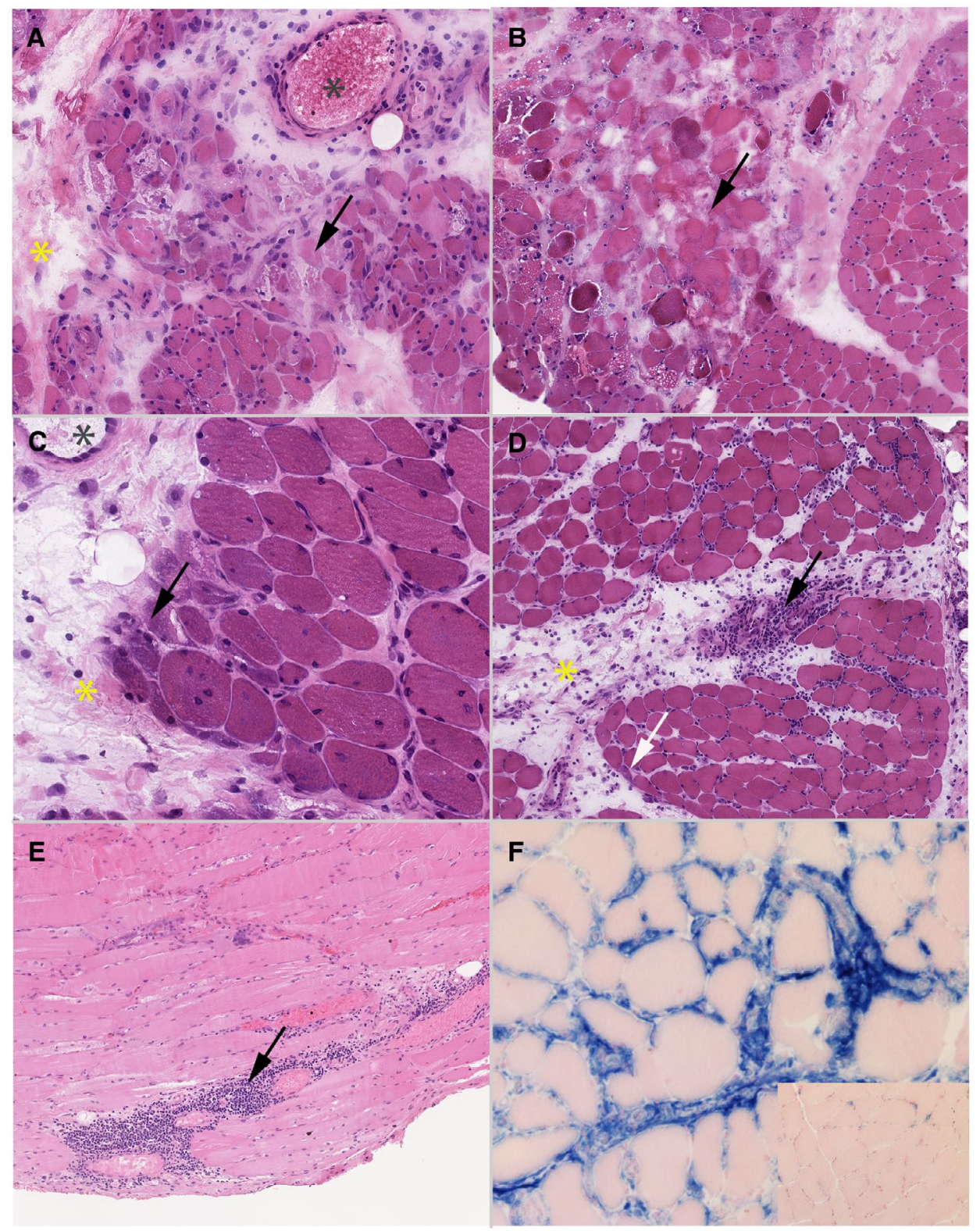

Figure 2. Morphological analysis. Optical microscopy. A to D: frozen sections, hematoxylin-eosin $(\mathrm{HE})$, magnification $\times 100$. C: paraffinembedded sections, hematoxylin-eosin, magnification $\times 100$. D: frozen section, histoenzymology, alkaline phosphatase (ALP) reaction using SK-5300 Vector Blue kit revealing ALP activity in blue, with eosin counterstaining, magnification $\times 200$. A: case without perifascicular atrophy but with several necrotic fibers (arrow), which is not specificDM features. A perimysial edema is observed too (yellow star). Moreover, blood vessels in perimysium are dilated (grey star). B: muscle biopsy showing a microinfarct, frequently seen in DM. A perimysial edema is observed too (yellow star). C: case with a marked perifascicular

weakness and frequent dysphagia $(6,10-11,23,34)$ presenting with an acute onset ( $<3$ months) (23).

Edema of the limbs is, therefore, a clinical gateway to IIM. Moreover, our clinico-sero-pathological findings suggest atrophy (arrow), which is seen in only $12 \%$ of the cases, associated with the internalization of the nucleus. A perimysial edema is observed too (yellow star) as well as enlargement of blood vessels in perimysium (grey star). D: there is a mild perifascicular atrophy (white arrow) and a strong perifascicular inflammatory infiltrate is present (block arrow), which both are specific-DM features. Finally, a perimysial edema is observed on HE stain (yellow star). E: perifascicular inflammatory infiltrate of mononucleated cells (black arrow). F: perimysial edema positive with ALP reaction (blue staining) compared to normal muscle (inset). ALP activity appears in blue, and the normal muscle in pink with the eosin counterstaining

that edematous myositis would nevertheless be more a subgroup of DM. Indeed, almost all patients had at least one classic DM feature (clinical, serological or pathological). Thirteen patients showed C5b-9 deposition on capillaries, 


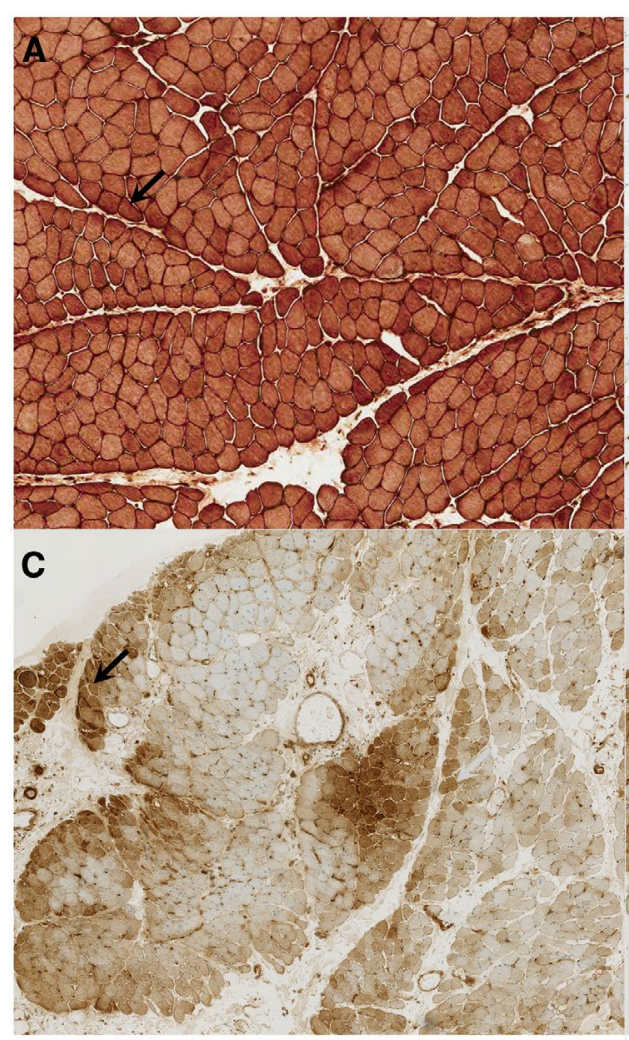

Figure 3. Immunochemistry analysis. Optical microscopy, frozen sections, magnification $\times 100(A$ and $B), \times 50(C$ and D). $A$ : anti-MHC I antibody. Diffuse positivity with perifascicular enhancement (black arrow). B: anti-C5b-9 antibody. Diffuse and strong deposition on endomysial capillary (inset: higher magnification). C and D: anti-MxA

among which only three cases did not express anti-MxA (cases 3, 4 and 8). Nine patients presented a classic DM skin rash, one of which had no deposit of C5b-9. Finally, eight patients had a positive DM-specific MSA. For only three patients (cases 3,4 and 6), there was not enough argument to diagnose DM. Since DM skin rash is observed in only half of our cases, this DM subgroup could expand the spectrum of DM 'sine dermatitis'. Others have also reported edematous myositis without DM skin rash (23), yet we also observed in $76.5 \%$ of the patients $(n=13 / 17)$ either a serological and/or a pathological feature of DM. An additional argument is a fact that only DM-specific antibodies were observed in our patients, including antiNXP2 which has been previously associated with an edematous form of DM (1). No MSAs associated with IMNM or AsyS were detected. Finally, edematous myositis was also frequently associated with malignancy, in the same range of other DM patients $(16,27,37)$, while this risk is considered lower in other myositis subgroups.

The pathological findings we observed correspond to described DM pathological features, as the presence of a perimysial inflammatory infiltrate see in all cases, the C5b-9 deposition on capillaries, even if it is not always specific for DM (31) and the positive DM-specific MxA immunostaining in the majority of cases $(72 \%)$ and in the same range

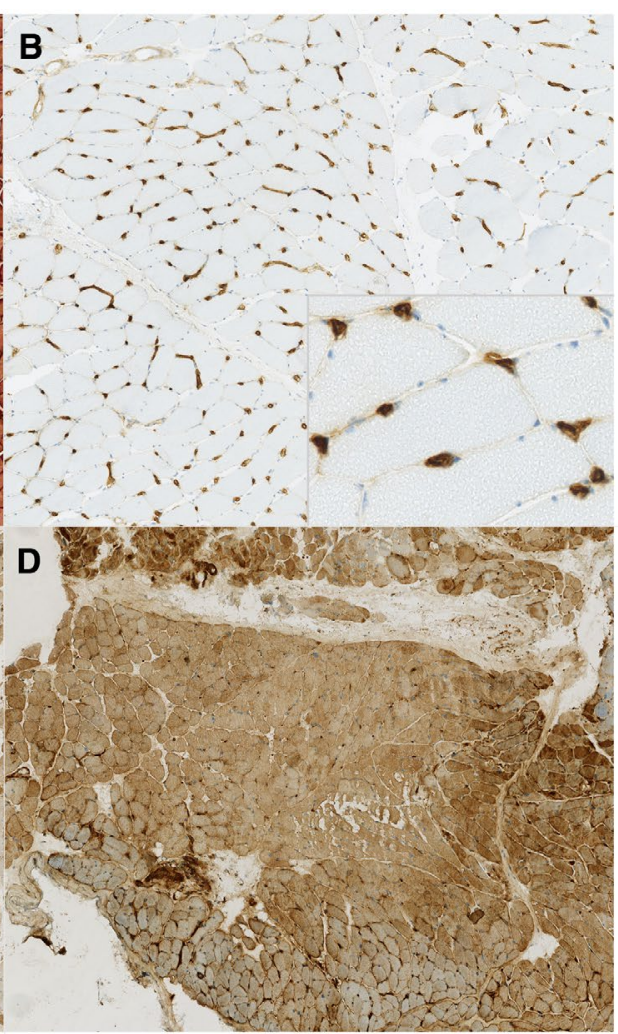

antibody, one case $\mathrm{MSA}^{+}$with positive NXP2 (C) and one case MSA (D). C: diffuse positivity with perifascicular enhancement (black arrow). D: diffuse and strong positivity

as reported in DM (19,30). In addition, 64\% of patients presented tubuloreticular inclusions, which have been described in DM (25) but also in other immune-mediated diseases $(20,26,29)$. Moreover, we observed a dilatation of blood vessels in the perimysium in the majority of cases, as previously reported (19), as well as the capillaries enlargement which is usual in DM $(8,32)$. Nevertheless, only a minority of edematous myositis patients met the other specific pathological criteria for DM classification $(7,21)$ with only $12 \%$ of cases with a perifascicular atrophy. Finally, there was a predominance of $\mathrm{CD}^{+} \mathrm{T}$ cells, while DM has been traditionally associated with $\mathrm{CD}^{+} \mathrm{T}$ cells infiltrates $(13,14)$.

Our MRI data could not differentiate between edematous myositis and non-edematous myositis hyperintensities. Of note, the presence of subcutaneous edema on MRI was frequent $(\mathrm{n}=5 / 9)$.

The comparison of edematous myositis to IIM controls demonstrated that endomysial capillary C5b-9 deposition and DM-specific antibodies were significantly more frequent in edematous myositis patients. Furthermore, there was no difference observed in comparison to DM without limb edema. Nevertheless, C5b-9 deposits are not a sufficient sign to make the diagnosis of $\operatorname{DM}(5,7,31,36)$ and three cases $(3-4,6)$ did not respond to any specific DM characteristic. This suggests that limb edema can be seen as a 
Table 3. Comparison between edematous myositis and idiopathic inflammatory myositis without edema

\begin{tabular}{|c|c|c|c|}
\hline Variables & $\begin{array}{c}\text { Non-edematous } \\
\qquad \mathrm{II}^{*}\end{array}$ & $\begin{array}{l}\text { Edematous } \\
\text { myositis }\end{array}$ & $P$-value ** \\
\hline Age at diagnosis & $46[33.2 ; 58.7]$ & 52 [45.2; 58.66] & 1 \\
\hline Women & $117(67.2 \%)$ & $10(58.8 \%)$ & 1 \\
\hline CK level (UI/L) & 5000 [1710; 10372.7] & 5118 [1654; 6928] & 1 \\
\hline Muscle weakness & $154(88.5 \%)$ & $15(88.2 \%)$ & 1 \\
\hline Dysphagia & $82(47.4 \%)$ & $12(70.6 \%)$ & 1 \\
\hline Cancer & $25(14.4 \%)$ & $4(25 \%)$ & 1 \\
\hline Raynaud & $46(26.74 \%)$ & $2(11.8 \%)$ & 1 \\
\hline Arthritis & $36(21.6 \%)$ & $0(0 \%)$ & 1 \\
\hline $\begin{array}{c}\text { Capillary C5b-9 } \\
\text { deposition }\end{array}$ & $47(37 \%)$ & $13(92.9 \%)$ & 0.003 \\
\hline $\begin{array}{l}\text { MCH class } 1 \\
\text { expression }\end{array}$ & $106(85.5 \%)$ & $14(100 \%)$ & 1 \\
\hline DM skin rash & $52(29.9 \%)$ & $9(52.9 \%)$ & 1 \\
\hline $\begin{array}{l}\text { Interstitial lung } \\
\text { disease }\end{array}$ & $74(44.6 \%)$ & $1(5.9 \%)$ & 0.07 \\
\hline \multicolumn{4}{|l|}{ MSA } \\
\hline DM-specific & & & $<0.00001$ \\
\hline MDA5 & $7(4 \%)$ & $0(0 \%)$ & \\
\hline Mi-2 & $12(6.9 \%)$ & $1(5.9 \%)$ & \\
\hline NXP2 & $3(1.7 \%)$ & $2(11.8 \%)$ & \\
\hline NXP2-SAE & $0(0 \%)$ & $1(5.9 \%)$ & \\
\hline SAE & $2(1.1 \%)$ & $1(5.9 \%)$ & \\
\hline TIF1 $\gamma$ & $3(1.7 \%)$ & $3(17.6 \%)$ & \\
\hline \multicolumn{4}{|l|}{ IMNM-specific } \\
\hline HMGCR & $31(17.8 \%)$ & $0(0 \%)$ & \\
\hline SPR & $34(19.5 \%)$ & $0(0 \%)$ & \\
\hline \multicolumn{4}{|l|}{ ASyS } \\
\hline Jo1 & $39(22.4 \%)$ & $0(0 \%)$ & \\
\hline PL-12 & $3(1.7 \%)$ & $0(0 \%)$ & \\
\hline PL-7 & $5(2.9 \%)$ & $0(0 \%)$ & \\
\hline Seronegative & $35(20.1 \%)$ & $7(41.2 \%)$ & \\
\hline Not done & $0(0 \%)$ & $2(11.8 \%)$ & $<0.00001$ \\
\hline
\end{tabular}

Abbreviations: $\mathrm{DM}=$ dermatomyositis; IMNM = immune mediated necrotizing myositis; IIM = idiopathic inflammatory myositis; $\mathrm{MSA}=\mathrm{my}-$ ositis specific antibodies; ASyS = antisynthetase syndrome.

${ }^{*} \mathrm{n}(\%)$ or median [Q1; Q3].

**Adjusted P-value Benjamini Hochberg.

symptom of IIM and that it will mainly concern patients suffering from a DM.

The underlying mechanism of edema remains unclear but myopathological features may provide some clues. The presence of perimysial edema and marked complement deposition in the endomysial capillaries may suggest an increase of capillaries permeability leading to leakage in the interstitial tissue. Indeed, complement cascade plays a key role in vessel permeability $(3,15,18,35)$. One cannot exclude that similar mechanisms occur in the skin, yet no skin biopsies were performed in our patients.

Despite the severity of edematous myositis, it is important to note that in the absence of malignancy and with immunosuppressive treatment, the outcome was good. Conversely, the presence of malignancy was associated with a poor prognosis. Finally, we found that our cases of edematous myositis were clinically characterized by muscular and cutaneous
Table 4. Comparison between edematous myositis and dermatomyositis without edema

\begin{tabular}{|c|c|c|c|}
\hline Variables & $\begin{array}{c}\text { DM without limb } \\
\text { edema* }\end{array}$ & $\begin{array}{l}\text { Edematous } \\
\text { myositis }\end{array}$ & $P$-value** \\
\hline $\begin{array}{l}\text { Median age at } \\
\text { diagnosis }\end{array}$ & $45[37.5 ; 57.5]$ & $52[45.2 ; 58.7]$ & 1 \\
\hline Female & $33(66 \%)$ & $10(58.8 \%)$ & 1 \\
\hline CK level (UI/L & 1800 [893; 8304] & 5118 [1654; 6928] & 1 \\
\hline Muscle weakness & $42(84 \%)$ & $15(88.2 \%)$ & 1 \\
\hline Dysphagia & $28(57.1 \%)$ & $12(70.6 \%)$ & 1 \\
\hline Cancer & $12(24 \%)$ & $4(25 \%)$ & 1 \\
\hline Raynaud & $8(16.3 \%)$ & $2(11.76 \%)$ & 1 \\
\hline Arthritis & $12(25 \%)$ & $0(0 \%)$ & 0.97 \\
\hline $\begin{array}{l}\text { Capillary C5b-9 } \\
\text { depositions }\end{array}$ & $26(66.7 \%)$ & $13(92.7 \%)$ & 1 \\
\hline $\begin{array}{l}\mathrm{MCH} \text { class } 1 \\
\text { expression }\end{array}$ & $31(86.1 \%)$ & $14(100 \%)$ & 1 \\
\hline DM skin Rash & $40(80 \%)$ & $9(52.9 \%)$ & 0.97 \\
\hline Gottron's papules & $21(42 \%)$ & $4(23.5 \%)$ & 1 \\
\hline $\begin{array}{l}\text { Periungueal } \\
\text { erythema }\end{array}$ & $22(44 \%)$ & $5(29.4 \%)$ & 1 \\
\hline $\begin{array}{l}\text { Erythema of the } \\
\text { eyelids }\end{array}$ & $8(16 \%)$ & $5(29.4 \%)$ & 1 \\
\hline $\begin{array}{l}\text { Flagellate } \\
\text { erythema }\end{array}$ & $19(38 \%)$ & $1(5.9 \%)$ & 0.48 \\
\hline Holster sign & $4(8 \%)$ & $2(11.8 \%)$ & 1 \\
\hline $\begin{array}{l}\text { Interstitial lung } \\
\text { disease }\end{array}$ & $9(18.7 \%)$ & $1(5.9 \%)$ & 1 \\
\hline \multicolumn{4}{|l|}{ MSA } \\
\hline MDA5 & $7(14 \%)$ & $0(0 \%)$ & 0.14 \\
\hline $\mathrm{Mi}-2$ & $12(24 \%)$ & $1(5.9 \%)$ & \\
\hline NXP2 & $3(6 \%)$ & $2(11.8 \%)$ & \\
\hline$N X P 2-S A E$ & $0(0 \%)$ & $1(5.9 \%)$ & \\
\hline$S A E$ & $2(4 \%)$ & $1(5.9 \%)$ & \\
\hline TIF1 $\gamma$ & $3(6 \%)$ & $3(17.6 \%)$ & \\
\hline Seronegative & 23 (46\%) & $7(41.2 \%)$ & 0.14 \\
\hline Not done & $0(0 \%)$ & $2(11.8 \%)$ & 0.14 \\
\hline
\end{tabular}

Italics denote significance values.

Abbreviations: $\mathrm{DM}=$ dermatomyositis; $\mathrm{MSA}=$ myositis specific antibodies.

${ }^{*} \mathrm{n}(\%)$ or median [Q1; Q3].

** Adjusted $P$-value Benjamini Hochberg.

involvement, and only one patient had interstitial lung disease, while no other signs of systemic involvement were found in the others. This "musculo-cutaneous" presentation is in agreement with the other published cases $(6,11,17,23,34)$.

To conclude, our study underlines that limb edema should be considered as a symptom of IIM and that edematous myositis are mostly DM. The complement cascade and vasculopathy seem to play a key role in its pathophysiology. Finally, edema of the limb associated with muscle impairment should be considered as one of the cutaneous signs suggesting a possibility of DM in clinical settings.

\section{AUTHOR CONTRIBUTIONS}

MD: collection of clinical and biological data, neuropathological analysis (morphology, immunohistochemistry, 
electron microscopy), interpretation of data, drafting and revision of manuscript. SLL: contributed to the neuropathological analysis (morphology, immunohistochemistry), revision of manuscript. OLC and CA: interpretation of the data and revision of manuscript. KM: database administration, statistical analysis, interpretation of the data and revision of manuscript. OB: interpretation of the data and revision of the manuscript. YA: study design, interpretation of the data and revision of manuscript. All of the authors contributed to the final draft of the manuscript.

\section{CONFLICT OF INTEREST}

The authors declare that they have no conflict of interest.

\section{DATA AVAILABILITY STATEMENT}

The data that support the findings of this study are available on request from the corresponding author. The data are not publicly available due to privacy or ethical restrictions.

\section{REFERENCES}

1. Albayda J, Pinal-Fernandez I, Huang W, Parks C, Paik J, Casciola-Rosen L et al (2017) Antinuclear matrix protein 2 autoantibodies and edema, muscle disease, and malignancy risk in dermatomyositis patients. Arthritis Care Res (Hoboken) 69:1771-1776.

2. Allenbach Y, Mammen AL, Benveniste O, Stenzel W, Allenbach Y, Amato A et al (2018) 224th ENMC International Workshop: Clinico-sero-pathological classification of immune-mediated necrotizing myopathies Zandvoort, The Netherlands, 14-16 October 2016. Neuromuscul Disord 28:87-99.

3. Auf dem Keller U, Prudova A, Eckhard U, Fingleton B, Overall CM (2013) Systems-level analysis of proteolytic events in increased vascular permeability and complement activation in skin inflammation. Sci Signal 6:rs2.

4. Benveniste O, Rider LG, Aggarwal R, Allenbach Y, Benveniste O, De Bleecker JL et al (2016) 213th ENMC International Workshop: outcome measures and clinical trial readiness in idiopathic inflammatory myopathies, Heemskerk, The Netherlands, 18-20 September 2015. Neuromuscul Disord 26:523-534.

5. Braczynski AK, Harter PN, Zeiner PS, Drott U, Tews DS, Preusse C et al (2016) C5b-9 deposits on endomysial capillaries in non-dermatomyositis cases. Neuromuscul Disord 26:283-291

6. Chai Y, Bertorini TE, Li YD, Mitchell C, Guan H (2011) Limb edema and anasarca associated with severe dermatomyositis: report of four cases. Neuromuscul Disord 21:439-442.

7. De Bleecker JL, De Paepe B, Aronica E, de Visser M, Amato A, Aronica E et al (2015) 205th ENMC International Workshop: pathology diagnosis of idiopathic inflammatory myopathies part II 28-30 March 2014, Naarden. The Netherlands. Neuromuscul Disord 25:268-272.

8. Emslie-Smith AM, Engel AG (1990) Microvascular changes in early and advanced dermatomyositis: a quantitative study. Ann Neurol 27:343-356.
9. Fayyaz B, Rehman HJ, Uqdah H (2019) Cancer-associated myositis: an elusive entity. J Community Hosp Intern Med Perspect 9:45-49.

10. Gorelik O, Almoznino-Sarafian D, Alon I, Rapoport MJ, Goltsman G, Herbert M et al (2001) Acute inflammatory myopathy with severe subcutaneous edema, a new variant? Report of two cases and review of the literature. Rheumatol Int 20:163-166.

11. Goussot R, Wettlé C, Le Coz C, Cribier B, Lipsker D (2016) Severe edematous dermatomyositis. Ann Dermatol Venereol 143:202-209.

12. Hepp P (1887) Über einen Fall von acuter parenhymatoser Myositis, welche Geschwulste bildete und Fluctuation vortauschte. Berlin Klin Wochenschr 24:389.

13. Hoogendijk JE, Amato AA, Lecky BR, Choy EH, Lundberg IE, Rose MR et al (2004) 119th ENMC international workshop: trial design in adult idiopathic inflammatory myopathies, with the exception of inclusion body myositis, 10-12 October 2003, Naarden, The Netherlands. Neuromuscul disord 14:337-345.

14. Iaccarino L, Ghirardello A, Bettio S, Zen M, Gatto M, Punzi L, Doria A (2014) The clinical features, diagnosis and classification of dermatomyositis. $J$ Autoimmun 49:122-127.

15. Jacob A, Hack B, Chiang E, Garcia JG, Quigg RJ, Alexander JJ (2010) C5a alters blood-brain barrier integrity in experimental lupus. FASEB $J$ 24:1682-1688.

16. Jakubaszek M, Kwiatkowska B, Maślińska M (2015) Polymyositis and dermatomyositis as a risk of developing cancer. Reumatologia 2:101-105.

17. Jung KD, Kim PS, Park HY, Kim CR, Byun JY, Lee DY et al (2012) Dermatomyositis associated with generalized subcutaneous edema and Evans syndrome. $J$ Am Acad Dermatol 66:144-147.

18. Khan MA, Maasch C, Vater A, Klussmann S, Morser J, Leung LL et al (2013) Targeting complement component 5a promotes vascular integrity and limits airway remodeling. Proc Natl Acad Sci U S A 110:6061-6066.

19. Lahoria R, Selcen D, Engel AG (2016) Microvascular alterations and the role of complement in dermatomyositis Brain 139(Pt 7):1891-1903.

20. Lee JY, Song SH, Kim YS, Lim BJ, Kim SI, Kim MS, Jeong HJ (2017) Tubuloreticular inclusions in peritubular capillaries of renal allografts. Pathol Res Pract 213:1185-1190.

21. Mammen AL, Allenbach Y, Stenzel W, Benveniste O, Allenbach Y, Benveniste O et al (2019) 239th ENMC International Workshop: classification of dermatomyositis, Amsterdam, the Netherlands, 14-16 December 2018. Neuromuscular Disord 30:70-92.

22. Mariampillai K, Granger B, Amelin D, Guiguet M, Hachulla E, Maurier F et al (2018) Development of a new classification system for idiopathic inflammatory myopathies based on clinical manifestations and myositis-specific autoantibodies. JAMA Neurol 75:1528-1537.

23. Milisenda JC, Doti PI, Prieto-González S, Grau JM (2014) Dermatomyositis presenting with severe subcutaneous edema: five additional cases and review of the literature. Semin Arthritis Rheum 44:228-233.

24. Monti S, Montecucco C, Cavagna L (2017) Clinical spectrum of anti-Jo-1-associated disease. Curr Opin Rheumatol 29:612-617.

25. Norton WL, Velayos E, Robison L (1970) Endothelial inclusions in dermatomyositis. Ann Rheum Dis 29:67-72. 
26. Nossent J, Raymond W, Ognjenovic M, Kang A, Chakera A, Wong D (2019) The importance of tubuloreticular inclusions in lupus nephritis. Pathology 51:727-732.

27. Olazagasti JM, Baez PJ, Wetter DA, Ernste FC (2015) Cancer risk in dermatomyositis: a meta-analysis of cohort studies. Am J Clin Dermatol 16:89-98.

28. Rider LG, Ruperto N, Pistorio A, Erman B, Bayat N, Lachenbruch PA et al (2017) 2016 ACR-EULAR adult dermatomyositis and polymyositis and juvenile dermatomyositis response criteria-methodological aspects. Rheumatology (Oxford) 56:1884-1893.

29. Schaff Z, Heine U, Dalton AJ (1972) Ultramorphological and ultracytochemical studies on tubuloreticular structures in lymphoid cells. Cancer Res 32:2696-2706.

30. Uruha A, Allenbach Y, Charuel JL, Musset L, Aussy A, Boyer O et al (2019) Diagnostic potential of sarcoplasmic myxovirus resistance protein A expression in subsets of dermatomyositis. Neuropathol Appl Neurobiol 45:513-522.

31. Uruha A, Nishikawa A, Tsuburaya RS, Hamanaka K, Kuwana M, Watanabe Y et al (2017) Sarcoplasmic MxA expression: a valuable marker of dermatomyositis. Neurology 88:493-500.

32. Vattemi G, Mirabella M, Guglielmi V, Lucchini M, Tomelleri G, Ghirardello A, Doria A (2014) Muscle biopsy features of idiopathic inflammatory myopathies and differential diagnosis. Auto Immun Highlights. 5:77-85.

33. Wagner E (1886) Ein fall von acuter polymyositis. Dtsch Arch Klin Med 11:241.

34. Watanabe M, Natsuga K, Arita K, Abe R, Shimizu H (2016) Generalized acute subcutaneous edema as a rare cutaneous manifestation of severe dermatomyositis. $J$ Eur Acad Dermatol Venereol 30:e151-e152.

35. Williams TJ (1983) Vascular permeability changes induced by complement-derived peptides. Agents Actions 13:451-455.

36. Yell PC, Burns DK, Dittmar EG, White CL 3rd, Cai C (2018) Diffuse microvascular C5b-9 deposition is a common feature in muscle and nerve biopsies from diabetic patients. Acta Neuropathol Commun 6:11.

37. Zahr ZA, Baer AN (2011) Malignancy in myositis. Curr Rheumatol Rep 13:208-15.

38. Zarrabi K, Choy T, Sweeney K, Desai V, Keresztes R (2017) Paraneoplastic edematous dermatomyositis: a rare syndrome observed in a case of small cell lung cancer. Clin Pract 7:982.

\section{SUPPORTING INFORMATION}

Additional supporting information may be found in the online version of this article at the publisher's web site:

\section{Fig S1}

Figure S1. Electronic microscopic analysis. A: case $\mathrm{MSA}^{+}$with positive TIF1 $\gamma$. B: case $\mathrm{MSA}^{-}$. Tubuloreticular inclusions (black arrow) are seen in the cytoplasm of endothelial cells. Basement membrane is thickened (B). Mt: mitochondria. BM: Basement membrane.

Table S1

Table S1. Patients' characteristics. 